his own clear conviction that the omission of intensive care is aligned to infanticide.

The activities within neonatal intensive care units (NICUs) are explained and illustrated very well. The glossary in the appendix will help those not familiar with the jargon of the NICU to find their way into this ethical minefield, without this handicap at least.

The opinions of seven paediatricians (including surgeons) who have published their views, are then reported. Their arguments are persuasive and erudite, although the inevitable repetition in this chapter is rather tedious.

Because they refer to United States law, the chapters on law and criminal liability are confusing, and probably of little value to the United Kingdom reader, except insofar as they help him or her to understand the arguments later in the book. This transatlantic difference was also reflected in the consideration of the financial aspects of intensive care and parental decisions.

The chapters on the opinions of the ethicists and on ethical criteria were extremely valuable. These, together with the extensive references provided, will equip the reader with a more sound basis for decision-making, explanation and argument in practice, and in teaching. The moral difference between doing harm by omission or commission is carefully discussed. The relationship between this and whether the multiplyhandicapped infant is really a person and whether the suffering inevitably associated with intensive care is justified if he is - is just one of the many unanswerable issues raised.

The final chapter, on procedures and recommendations, left me feeling slightly chilled. For those who have shared with parents in the difficult decision as to the degree of treatment to be provided for a particular baby's problem, the idea that a committee should coldly assess the relevant factors is probably untenable. Even if the morally relevant factors could be defined and presented adequately, the potential for an increase in suffering to the family and the caring staff by such a procedure would not be outweighed by the fairness to the baby - unless one does not believe in the normal protective love of most parents, or in the integrity of most doctors. Fortunately, the chapter and the book finish with a plea to consider the needs of the dying baby and the bereaved parents: 'Having made or had some part in a selective nontreatment decision, bereaved persons need a private place to cry, to think, perhaps to pray - and to hold the body of a child too seriously handicapped to continue living'.

GRAHAM CLAYDEN Department of Paediatrics, United Medical and Dental Schools of Guys and St Thomas's Hospitals, London, SE1 $7 E H$.

\section{The Patient Patients - Women and Their Doctors}

Helen Roberts, 143 pages, London, $£ 3.95$ (paperback), Pandora, 1985

'The clear message of the women's health movement has been that health must be delivered back into the hands of those most affected by health. And they are not doctors, but ourselves'.

This statement by a distinguished feminist sociologist deserves attention. As Ms Roberts says in her first chapter 'This isn't an anti-doctor book, but that doesn't mean that doctors will see it as "fair". The doctor/patient relationship isn't a "fair one" '. What this book does is to illustrate some of the hidden dimensions of power between doctors and their women patients and to suggest what might be done to redress the balance.

Ms Roberts is a senior researcher at Bradford and Ilkely Community College. Her original research, on which the present book is based, was published with Michelle Barrett back in 1978 in Women, Sexuality and Social Control, as Doctors and Their Patients The Social Control of Women in General Practice. In this she is in the tradition of Erving Goffman - extending his thinking out from institutions into general practice. Sadly, since her original work, little has been done to extend the basic teaching of sociology to medical students or more importantly to general practitioner trainees.

On the other hand most of the women trainees noted in her statistical tables of 1977 will by now have moved on into general practice and so have given women a much greater opportunity of having a woman doctor.

Her main recommendations as to the improvement of general practitioner services and relationships are appropriate and will prick the consciences of general practitioner readers sensitive enough to read that far.

For readers of this journal the author makes two interesting suggestions. She rejects the stereotype that 'women's energies in our kind of society appear to be devoted to doing good and feeling bad'. Though against 'do it yourself medicine' she feels that to take more responsibility for their own health women should define themselves as basically healthy. Then in the field of the selection and training of medical students she feels it 'might be easier to teach those who care to become doctors, than to teach doctors to care'.

She certainly helps us understand more of how our women patients probably think about us. I was, for example, particularly struck by her recording the embarrassment of a patient waiting in an examining room for a chaperone to be sent for - and the social implications of this.

On the other hand in some areas her feminism undermines the credibility of her common-sense sociological approach. She criticises a medical textbook containing a problem case that begins 'a very attractive girl of 19 , new to the practice ... she was wearing an exceptionally short skirt and moved provocatively' - Having discussed the case Ms Roberts goes on, 'how would the trainee GP have felt if she or he were confronted with a rather different case study beginning 'a very attractive boy of 19 came to the practice ... He was wearing an exceptionally close fitting pair of jeans and moved provocatively'. How indeed? Just as wary I hope. In my work with delinquent adolescents I demand a chaperone as much with boys as girls. This sexual 'inversion' just doesn't work as a practical example; people are people, and flirts are flirts.

Even if doctors don't read this book the patients will and by their pressure perhaps make us better doctors - for our patients of both genders.

JAMES F FISHER General Practitioner, 85 Castle Lane, Boumemouth, Dorset $B H 93 L Q$

Biomedical Research Involving Animals Proposed International Guiding
Principles Proceedings of the XVIIth CIOMS Round Table Conference, Editors Z Bankowski and N Howard-Jones, 218 pages, Switzerland, £10, The Council for International Organisations of Medical Sciences, 1984

CIOMS Round Table Conferences are designed to provide interdisciplinary forums to enable the scientific and lay communities to express their views on topics of current concern unhampered by administrative, political, or other 